\title{
Effects of Excessive Use of Mobile Phone and Psychological Hazards among Staff Nurses
}

\author{
Omprakash Swami ${ }^{1}$, Dr. Bhartendra Sharma ${ }^{2}$, Giriraj Prasad Soni ${ }^{3}$ \\ ${ }^{1}$ PHD Scholar, Mahatma Gandhi Nursing College, Sitapura, Jaipur \\ ${ }^{2}$ Professor (Research Guide) Mahatma Gandhi Nursing College, Sitapura, Jaipur \\ ${ }^{3}$ Dean \& Principal, Mahatma Gandhi Nursing College, Sitapura, Jaipur \\ Email id of corresponding author: opswami[at]mgumst.org
}

\begin{abstract}
Background: In the modern era of the 21st century, mobile phones have been part of our life and it has revolutionized our lifestyle. We all communicate with one another; retrieve information for education, and also using for entertainment purpose. Mobile phone with its own demerits such as it causes various health hazards ranging from insomnia, numbness of fingers, and irritability to headache, anxiety, and dreadful addiction.1 Material \& Methods: Quantitative Research Approach use for this study. Quasi experimental design (Nonequivalent control group design) was use in this study. Study conducted at Imperial Hospital, Jaipur on 40 staff nurses. For the collection of data Convenient Sampling Techniques were used. Result: Severity of mobile phone uses in control group in excessive user in pre test was $20 \%$ (100\%) and in post test of control group is $14 \%$, $4 \%$ were moderate user, $2 \%$ were mild users. in the case group data present to excessive user in pre test was $20(100 \%)$ and in Post group of case group excessive users is $0 \%$, Moderate users is $0 \%$ mild user is 16 (100\%) and normal user was 04 (100\%). Discussion: The study concluded an urgent to develop a policy regarding use of mobile phone during working hours. Urgent need to update the information regarding effective use of mobile phone during working hours and also decrease the psychological hazards after training programme among staff nurses.
\end{abstract}

Keywords: Effects, Excessive, Use, Mobile phone, Psychological hazards

\section{Introduction}

Cell phones are a comparatively novel and evolving technology. Possible benefits of this technology still emerge, so do the potential psychosocial risks. For example, one psychosocial risk is user stress, which appears to be associated with feeling compelled to promptly answer cellphone activity so as to take care of spontaneity and access with others. Potential psychosocial risks also include disruptions in sleep; the user's risk of exposure to cyber bullying, particularly the unwanted exposure of photographs and/or videos of the victim; and overuse, particularly among adolescents. With reference to the latter phenomenon, the boundaries among overuse, misuse, dependence, and addiction are not scientifically clear. Therefore, while cell phones are a convenient and expedient technology, they're not without their potential psychosocial hazards. 2

Young people using mobile phones excessively constitute a risk group in terms of addiction. A survey on this issue reported that young people are overly dependent to their mobile phones, and show some signs of addiction. People use their mobile phones to send and receive short messages, and spend more than 5 hours on their mobile phones daily. The young people who can't limit their mobile phone use may experience serious academic, financial, behavioural, and psychological problems. Academic performance is one of the important areas effective on life satisfaction of college students. Although an improvement in face to-face communication skills of nurses has a positive contribution to their professional lives, their extensive use of mobile phones can lead to some problems. 3

The prevalence of mobile phone usage was 70\%. Calling facility $(94.2 \%)$ was used more than the SMS (67.6\%).
Health problems like headache, earache, tinnitus, painful fingers and restlessness etc., were found to be positively associated with mobile phone usage. 4

A survey study conducted in March 2014.30 questions were emailed to the 10978 of medical surgical nurses. Out of 10978825 were respondent who select in inclusion criteria. The use of mobile phone while working in the hospital was reported by 78.1 of respondents. This study found that nurses frequently use mobile phone for non-work related activities during the working hours.5

\section{Methodology of the Proposed Research}

Research Approach: The research approach will be used in this study is Quantitative Research Approach

Research Design: The research design will be used in this study is Quasi Experimental Research DesignNonequivalent control group design.

Research Setting: Imperial Hospital for the pilot study.

Population: Target population (Staff Nurse of Imperial Hospital of Jaipur)

Accessible population: (Staff Nurses Available during data collection)

Sample: Staff Nurses in a Imperial Hospital at Jaipur

Criteria for the selection of sample (Inclusion \& Exclusion):

Volume 10 Issue 12, December 2021

www.ijsr.net

Licensed Under Creative Commons Attribution CC BY 


\section{Inclusion criteria}

1) Staff nurses working in selected hospital of Jaipur\& who are Available during time of data collection.

2) Staff nurses who are willing to participate \& given consent.

3) Staff nurses who are using the mobile phone during duty hours.

\section{Exclusion criteria}

1) Staff nurses who are not willing to participate in this study.

2) Staff nurses who are not using the mobile phone

3) Staff nurses who are not available during data collection, long leave $\&$ sick leave

Sampling Technique: Convenient sampling

\section{Result}

Table 1: Comparing treatment effect of PMPUQ-svin both groups

\begin{tabular}{|c|c|c|c|c|c|}
\hline Groups & Pre & Post & Paired t-test & P-Value & Significance \\
\hline Control Group & $69.4 \pm 2.06$ & $62.8 \pm 8.38$ & 3.78 & 0.00064 & \multirow{2}{*}{ Highly significant } \\
\hline Case Group & $71 \pm 2.214$ & $28.75 \pm 3.88$ & 38.2 & 0.000001 & \\
\hline
\end{tabular}

Table 2: Comparing treatment effect of mobile phone addiction in both groups

\begin{tabular}{|c|c|c|c|c|c|}
\hline Groups & Pre & Post & Paired t-test & P-Value & Significance \\
\hline Control Group & $55.25 \pm 1.97$ & $51.85 \pm 8.58$ & 1.701 & 0.0527 & Not significant \\
\hline Case Group & $55.2 \pm 1.69$ & $18.05 \pm 3.87$ & 33.53 & 0.000001 & Highly significant \\
\hline
\end{tabular}

Table 3: Comparing change in score between control and case group

\begin{tabular}{|c|c|c|c|c|c|}
\hline Variables & Control Group & Case Group & t-test & P-Value & Significance \\
\hline PMPUQ & $6.6 \pm 7.62$ & $42.25 \pm 4.83$ & -17.23 & 0.000001 & Highly \\
Smart phone addiction & $3.4 \pm 8.7$ & $37.15 \pm 4.83$ & -14.77 & 0.000001 & significant \\
\hline
\end{tabular}

Table 4: Severity of mobile phone uses

\begin{tabular}{|c|c|c|c|c|}
\hline \multirow{2}{*}{ Characteristics } & \multicolumn{2}{|c|}{ Control group } & \multicolumn{2}{c|}{ Case group } \\
\cline { 2 - 5 } & Pre & Post & Pre & Post \\
\hline Excessive uses & $20(100 \%)$ & $14(70 \%)$ & $20(100 \%)$ & 0 \\
\hline Moderate uses & 0 & $4(20 \%)$ & 0 & 0 \\
\hline Mild uses & 0 & $2(10 \%$ & 0 & $16(80 \%)$ \\
\hline Normal uses & 0 & 0 & 0 & $4(20 \%)$ \\
\hline
\end{tabular}

Table 5: Knowing knowledge of negative impact of mobile phone uses

\begin{tabular}{|c|c|c|c|c|}
\hline \multirow{2}{*}{ Characteristics } & \multicolumn{2}{|c|}{ Control group } & \multicolumn{2}{c|}{ Case group } \\
\cline { 2 - 5 } & Pre & Post & Pre & Post \\
\hline Severe addiction & $20(100 \%)$ & $18(90 \%)$ & $20(100 \%)$ & 0 \\
\hline Moderate addiction & 0 & $1(05 \%)$ & 0 & 0 \\
\hline Mild addiction & 0 & 0 & 0 & 0 \\
\hline Normal Addiction & 0 & $1(05 \%)$ & 0 & $20(100 \%)$ \\
\hline
\end{tabular}

Frequencies and percentage for the analysis of demographic variables, the Impact of mobile phone training session on staff nurses before and after administering the training programme was analyzed by using mean and standard deviation. The effectiveness of structured teaching programme/training programme was analyzed by using paired ' $t$ ' test. The association between selected demographic variables and impact of mobile phone training session scores was determined by paired t test test. The results obtained were considered statistically significant at 5 percent level of significance $(\mathrm{p} \leq 0.05)$. Data was presented in the form of tables, graphs and diagrams.

\section{Discussion}

The study concluded an urgent to develop a policy regarding use of mobile phone during working hours. The prevalence of mobile phone usage was used more than the SMS. Health problems like headache, earache, tinnitus, painful fingers and restlessness etc., were found to be positively associated with mobile phone usage. therefore an urgent need to update the information regarding effective use of mobile phone during working hours and also decrease the psychological hazards. minimizes the usability of mobile phone during emergency and critical work also minimize the addiction of mobile phone by the nurses can able to provide effective nursing care to the patient.

\section{Conclusion}

The study concluded an urgent to develop a policy regarding use of mobile phone during working hours. The prevalence of mobile phone usage was used more than the SMS Minimizes the usability of mobile phone during emergency and critical work also minimize the addiction of mobile phone by the nurses can able to provide effective nursing care to the patient.

\section{References}

[1] Sarkar Tarun Kumar, Taneja Neha, Jana Pulak Kumar, Effect of mobile phone overuse on health of medical students: International Journal of Medical Science and Public Health.2019 Dec.; 8 (1): 91-94

[2] RandyAs, Cell phones: the psychosocial risks, Innov Clin Neurosci.2013 Jan; 10 (1): 33-7.

[3] DayapogluNuray, KavurmaciMehtap, Karaman Seda, The Relationship between the Problematic Mobile Phone Use and Life Satisfaction, Loneliness, and Academic Performance in Nursing Students; International Journal of Caring Sciences May- August 2016 Volume 9 | Issue 2| Page 647

[4] DaeiAzra. Nomophobia and health hazards: smartphone use and addiction among university students. Int $\mathbf{J}$ Prev Med.2019 Nov28; 10: 202.

\section{Volume 10 Issue 12, December 2021 www.ijsr.net}




\section{International Journal of Science and Research (IJSR)}

ISSN: 2319-7064

SJIF (2020): 7.803

[5] Gill PS, Kamath Ashwini, GillTS. Distraction an assessment of smartphone usages in health care work settings. Risk ManagHealthc policy, 2012; 5: 105-114.

Volume 10 Issue 12, December 2021

www.ijsr.net

Licensed Under Creative Commons Attribution CC BY 